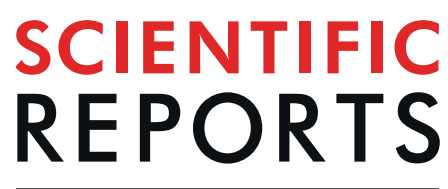

natureresearch

\title{
OPEN
}

Published online: 29 January 2020

\section{Author Correction: A novel ruthenium (II)-derived organometallic compound, TQ-6, potently inhibits platelet aggregation: Ex vivo and in vivo studies}

\section{Chih-Hsuan Hsia, Marappan Velusamy, Joen-Rong Sheu, Themmila Khamrang, Thanasekaran Jayakumar, Wan-Jung Lu, Kuan-Hung Lin \& Chao-Chien Chang}

Correction to: Scientific Reports https://doi.org/10.1038/s41598-017-09695-z, published online 25 August 2017

The original version of this Article omitted an additional affiliation for Wan-Jung Lu. The correct affiliations for Wan-Jung Lu are listed below:

Graduate Institute of Medical Sciences, College of Medicine, Taipei Medical University, Taipei, 110, Taiwan

Department of Medical Research, Taipei Medical University Hospital, Taipei, 110, Taiwan

Department of Pharmacology, School of Medicine, College of Medicine, Taipei Medical University, Taipei, 110, Taiwan

This error has now been corrected in the HTML and PDF versions of the article.

\begin{abstract}
(c) (i) Open Access This article is licensed under a Creative Commons Attribution 4.0 International License, which permits use, sharing, adaptation, distribution and reproduction in any medium or format, as long as you give appropriate credit to the original author(s) and the source, provide a link to the Creative Commons license, and indicate if changes were made. The images or other third party material in this article are included in the article's Creative Commons license, unless indicated otherwise in a credit line to the material. If material is not included in the article's Creative Commons license and your intended use is not permitted by statutory regulation or exceeds the permitted use, you will need to obtain permission directly from the copyright holder. To view a copy of this license, visit http://creativecommons.org/licenses/by/4.0/.
\end{abstract}

(C) The Author(s) 2020 